\title{
Contemplating Co-creator Rights in Archival Description ${ }^{\dagger}$
}

\author{
Anne J. Gilliland \\ Department of Information Studies, 212 GSEIS Building, Box 951520, \\ University of California Los Angeles, Los Angeles, CA 90095-1520, USA, \\ $<$ Gilliland@gseis.ucla.edu>
}

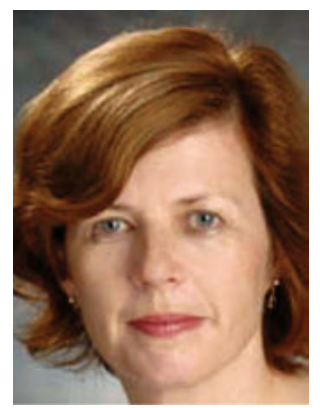

Anne J. Gilliland is a Professor and Director of the Center for Information as Evidence in the Department of Information Studies at the University of California, Los Angeles (UCLA). Her work relates to the design, evaluation, and history of recordkeeping, cultural, and community information systems and practices, and metadata creation and management. Recent research activities include the Building the Future of Archival Education and Research Initiative (AERI), the Metadata Archaeology Project, and the InterPARES $1 \& 2$ Projects. Dr. Gilliland is a Fellow of the Society of American Archivists.

Gilliland, Anne J. Contemplating Co-creator Rights in Archival Description. Knowledge Organization. 39(5), 340-346. 23 references.

\begin{abstract}
Archival description and recordkeeping metadata more broadly can be instrumental in perpetrating, as well as in providing for recovery from and reconciliation regarding historical injustices and silences in the historical record. This paper argues that archivists have an ethical imperative to pursue descriptive mechanisms for representing both creator and co-creator worldviews and experiences, and supporting diverse user needs and concerns, within and relating to a given community of records. Drawing upon a study of professional and political discourse surrounding the development of the Aboriginal and Torres Strait Islander Data Archive (ATSIDA) that was conducted as part of the Metadata Archaeology Project, this paper discusses how acknowledging and incorporating co-creator rights and needs in description according to Indigenous protocols provides one approach to addressing this imperative. It concludes that further research and development is needed to identify whether such an approach might also support the interests and practices of other communities of records or whether a rethinking of archival descriptive practices and standards is necessary in order to address concerns about ethical and power differentials within the archival multiverse.
\end{abstract}

Received 19 June 2012; Accepted 19 June 2012

$\dagger$ The author would like to acknowledge the assistance of Alex Byrne, Elizabeth Mulhollan, Matt Poll, and Kirsten Thorpe with
the ATSIDA study, and to pay her respects to Indigenous Elders and peoples past and present. She would also like to thank
Kimberly Anderson and Michelle Caswell for their comments on this paper.

\subsection{Introduction}

Records and other archival materials such as research data are more likely to be conceived of and thus described as bureaucratic instruments and primary sources for scholarly use than in terms of the central and instrumental role they can play in the lives, needs, and emotions of individuals, families, and communities to whom they pertain. Much of the capacity of these materials to effect and record actions and to en- gender affect is integrally bound up with the recordkeeping metadata associated with them (i.e., all or any of the various traces, statements, and surrogates that are made by or about the materials and their various contexts over time, including archival description). However, the metadata generated when these materials are first created and used, or by the government, academic, and other institutional repositories that later preserve and provide access to them, rarely directly or adequately addresses the concerns and needs 
of all parties involved in their creation and use within the relevant community of records.

The archival concept of co-creatorship has been proposed as a way to acknowledge, give voice to, and describe the roles of those who were involved with the creation of the record and its metadata as contributors, subjects, victims, or legatees rather than as the official authors. However the identification of these parties as co-creators challenges traditional archival ideas about provenance. It also elicits controversy as to whether a designation as co-creator would convey a false sense of agency on the part of those who were coerced or unwitting participants in the activity that led to the creation of the record. Drawing upon a study of the Aboriginal and Torres Strait Islander Data Archive (ATSIDA) that was conducted as part of the Metadata Archaeology Project, this paper contemplates how a community protocols-based approach supports co-creator rights and recognition in description and metadata reconciliation. It concludes by asking whether a community protocols approach might help archival description to address the needs, interests, and beliefs of other such co-creator communities, or whether the profession needs to rethink its current descriptive practices and standards.

\subsection{Framing within archival discourse}

Influenced by postmodern scholarship, archival studies researchers have questioned the power dynamics underlying the impulses behind and processes of archiving and their effects, for example, "Do archivists participate actively in the construction of a record's meanings and significances? ... Does the archivist have a moral obligation to engage the marginalized and excluded voices in records?” (Duff and Harris 2007, 133). Three distinct strands of recent discourse have focused on the implications of power and representation for historically subjugated, marginalized, or subaltern communities: post-colonial analyses of the role of the archive and archival practices in colonialism (e.g., Stoler 2009; Ghosh 2005), the community archives movement (e.g., Flinn et al. 2009), and the movement to promote Indigenous protocols for archival materials (e.g., Nakata et al. 2006; McKemmish et al. 2011b). Each strand is deeply cognizant of the often difficult and intertwined histories that are inevitably reflected in their equally intertwined archival legacy. At the same time, each strand raises its own questions about how mainstream archival description reflects and shapes interpretations of these materials in favor of dominant or élite interests, and often in the process subordinates or excludes the narratives, needs, and perspectives of communities who were under-empowered, unwitting, or unwilling participants in the creation of documentation about them.

Institutional consultation or research and development partnerships with these communities, as well as community self-determination over their own materials, have been proposed as ways to redress these concerns and include more marginalized and excluded voices. Archival description that directly addresses community needs and perspectives, however, must go beyond simply enhancing access for these communities to materials by and about them that are held by individual repositories. It must also be able to traverse, explain, "set the record straight" (McKemmish et al. 2011a), and reconcile layers of metadata for diverse such materials that today might be dispersed across many locations and repositories, and that have been created over time under different political and social circumstances and according to different worldviews.

\subsection{Co-creatorship, communities of record, and the archival multiverse}

According to traditional archival theory, archival description plays several roles: elucidating the circumstances of creation and creative intent behind the materials being described, exposing their documentary inter-relationships, supporting user assessment of their reliability and continued authenticity, and promoting findability. There are many complexities inherent in arranging and describing archival evidence and information in ways that can cope with variant worldviews and the shifting terminology, conceptualizations, and ascribed meanings and values that might occur across the existence of the preserved materials. Grappling with such ethical and human rights considerations as integrating community protocols, undertaking community-centric re-description, or "reconciling" legacy metadata adds to this complexity.

Paradigmatically, archival description privileges context over content. It is collective, hierarchical, and bound by the twin principles of Provenance and the Sanctity of Original Order. Provenance, the primary mechanism though which the identity of the creator is established and also the main intellectual access point to a collection of archival materials, recognizes only the author (juridical or human), collector, or donor as possible creators. The act of designating provenance is an acknowledgment of the authority and responsibility and, by implication, reinforces the 
power status of, the official creating entity over any other party involved in the creation of the materials. Such parties, if mentioned at all, are treated as subjects or objects of those materials and may not necessarily even be acknowledged through additional descriptive access points. Although original order has diminished in importance as a descriptive principle as archival materials are increasingly digitized or borndigital, several expanded conceptualizations of provenance have been proposed to address the multiple parties and simultaneity that are increasingly characteristic of the creation of records and archival materials. These include functional provenance (Bantin and Bernbom 1996), ethnicity as provenance (Wurl 2005), and simultaneous multiple provenance and parallel provenance (Hurley 2005a; 2005b).

Hurley's ideas with regard to recognizing other parties to the creation of the records as co-creators who have rights in those records resonate strongly with rights assertions over Indigenous knowledge contained in the U.N. Declaration on Indigenous Rights (United Nations 2007). Among these are the right to be acknowledged as a co-creator and the right to ensure that archival description reflects co-creator perspectives, experiences, expressions, and ways of knowing. Co-creatorship and its associated matrix of relationships, rights, and obligations can in turn be situated within a cluster of conceptually-related constructs emerging from recent archival theory-building and applied research that are challenging traditional archival description. Among these is the notion of a community of records, i.e., the web of relationships between actions, records, and recordkeeping traditions, practices and conventions within one particular community of memory (Bastian 2003, 5) that remembers a common past (Ketelaar 2005, 44). This web is often documented or made visible through recordkeeping metadata. If one means by which identity can be constructed in knowledge organization is through relationships between documents (Furner 2009), could the relationships between members of a community of records also serve as a basis upon which co-creator identities might be identified?

Two other emerging constructs in this cluster are archival reconciliation and the archival multiverse. Both speak to the need to situate and account for archival description within shifting temporal and sociopolitical circumstances and plural cultural and recordkeeping perspectives. Archival reconciliation, an approach developed through Indigenous community research partnerships in Australia, involves acknowledging the impact of past and existing recordkeeping and archival structures and practices, and situating current and future structures and practices within the archival multiverse (Gilliland forthcoming). The archival multiverse encompasses "the plurality of evidentiary texts (records in multiple forms and cultural contexts), memory-keeping practices and institutions, bureaucratic and personal motivations, community perspectives and needs, and cultural and legal constructs" (AERI PACG 2011).

\subsection{The Metadata Archaeology Project}

The Metadata Archaeology Project, conducted by the author between 2010 and 2012, used discourse analysis, ethnography, and autoethnography to examine metadata considerations in various archival contexts where aspects of the above discursive strands could be observed in action, to explore issues of incommensurability and intersectionality that might arise, and to position and account for the author's place within the study and the discourse (Gilliland 2011). The result was a series of deep descriptive studies of which the development of ATSIDA, discussed below, was one.

\subsection{A protocols-based approach to archival description}

In 1995, the Australian Library and Information Association published the first edition of the Aboriginal and Torres Strait Islander Library and Information Resources Network (ATSILIRN) Protocols for Libraries, Archives and Information Services. A key philosophy underlying the ATSILIRN Protocols is a "both ways" or "two ways" approach that is based upon "equal respect for both Indigenous and 'western' languages, knowledge and learning approaches" (ATSILIRN 2005). The ATSILIRN Protocols recognize the moral rights of Aboriginal and Torres Strait Islander peoples as the owners of their knowledge and the importance of their involvement in deciding issues arising from Aboriginal and Torres Strait Islander content and perspectives in documentary materials, media, and traditional cultural property. They also encourage Indigenous participation in the governance and operation of libraries, archives and information services. The $A T$ SILIRN Protocols influenced the 2007 development of the Native American Protocols for Archival Materials in the United States (First Archivist Circle 2007), as well as the philosophy, structure, and activities of ATSIDA.

As the ATSILIRN Protocols point out, among the many perspectives present in Australian library and 
archival materials relating to the Indigenous population are "those of the colonist, policeman and magistrate as well as those of the historian, anthropologist and social commentator." The perspectives that are notably absent, however, are those of Indigenous people themselves. By definition, such protocols acknowledge Indigenous people as co-creators of these materials and promote their rights. It should be noted, however, that the designation of co-creator has been the subject of debate in archival discourse relating to human rights as well as in mainstream description. Some human rights archivists have argued that in cases where records are implicated in egregious human rights violations, the designation mischaracterizes the role of victims within the community of records and implies more agency on their part than was ever possible.

\subsection{Bringing them home}

Bringing Them Home (BTH), the 1997 Report of the National Inquiry into the Separation of Aboriginal and Torres Strait Islander Children from Their Families, highlighted the historical roles that bureaucratic recordkeeping and metadata played in the identification, forcible removal from their families and communities, and assimilation of Australian Indigenous children between 1869 and the 1970s (Australian Human Rights Commission 1997). Records from this period routinely applied the official bureaucratic terminology of those carrying out the programs and activities associated with the removals and used English names and designations to refer to Indigenous Country, locations, communities, and individuals. Both bureaucratic records and materials gathered or created by anthropologists, naturalists, and private collectors from or about Indigenous communities or individuals during this time could include intimate and often derogatory information about Indigenous people; or record language, stories, songs, and other elements that were considered secret or sacred by Indigenous people. While the structures, categorizations, and language used in describing these records and other materials are evidence of colonial, bureaucratic, and scholarly attitudes and activities of the time, they remain far from benign in terms of both their historical and continuing effect and the affect on Indigenous individuals, families, and communities.

The BTH report also focused on the ways in which archives today might support redress to those who had been removed and the inclusion of their lives, experiences, and voices within the national memory. It pointed out that Indigenous family history research using what bureaucratic records remain in existence is key to certifying descent from the Indigenous peoples of Australia and acceptance as Indigenous by the Indigenous community. However, the report identified several barriers to using these records for such purposes. For example, they were not easy to use in the ways that Indigenous community members needed to use them because records were described according to provenance (i.e., the agency, program, or individual responsible), and there was no consolidated name index. Moreover, references to individuals, often idiosyncratically spelled, or ambiguously or unclearly designated, were scattered through the surviving records of many different agencies, including government offices, schools, and healthcare providers.

The report called for description of these materials in ways that would assist Indigenous persons in their quests while protecting their privacy and guarding against any future compilation of dossiers about them. In effect, it was asking not only for more complete representation of a past that was inadequately captured in official records, but also for something new and ethically, theoretically and practically challenging for those holding records-the creation of alternate descriptions that directly addressed Indigenous community worldviews, concerns, and needs. ATSIDA represents one of several archival initiatives that have addressed the report's concerns.

\subsection{The Aboriginal and Torres Strait Islander Data Archive (ATSIDA)}

ATSIDA is a multi-site data archive hosted by a network of Australian universities that is also a digital "keeping place" for materials of a diversity of provenances relating to Australian Indigenous people. As a data archive, it supports forms of descriptive access that moves it beyond conventional archival approaches, including item and within-item access, multiple arrangement and presentation schemes, and community annotation capabilities. Initiated in 2010, its content includes extracts of official records such as Indigenous censuses and police reports; opinion polls and surveys; and digital versions of genealogies, stories, songs, oral histories, and other expressions of Indigenous knowledge, memory, and ritual. It is exemplary not only because of its data archive approach, but also because its ethos derives from a set of protocols that were developed in association with a Reference Group composed of senior Indigenous Australian academics and researchers on Indigenous 
issues (ATSIDA 2010). Commitment to community consultation, the building of mutual trust, and negotiating and reconciling various rights and interests thus lie at the heart of ATSIDA.

While such relationship-building can be drawnout, highly charged, and messy, the need can be intensely urgent because of the very real effect and affect of the materials and their metadata held by ATSIDA on the lives, identities, and welfare of living Indigenous individuals, families, and communities. The work of ATSIDA illustrates the ways in which the same records with alternate culturally and situationally appropriate metadata, including communitysupplied annotations (increasingly via social media), when managed in accordance with Indigenous needs, concerns, and beliefs, and with professional awareness of the urgency that is often involved, can support redress for that violence and the reconstruction of identity, memory, and lives.

ATSIDA has identified various challenges for description. For example, description of the archival materials, typically created at one specific moment, must be capable of evolving as circumstances shift. One illustration that was provided during the ATSIDA study related to the description of sacred or secret materials. The identification and classification of materials as sacred or secret tend to be contingent on other factors within the community and thus may be subject to change. For example, ceremonies no longer being practiced because they have been lost or forgotten might be closed, but might be opened if the community were able to recover the ceremony by re-learning it from archival materials such as recordings and photographs of non-Indigenous provenance or from other documentation that might yet be uncovered.

Another challenge raised during the study was the risks and questions associated with metadata creation at increasingly granular levels, as well as with its promulgation online. For example, granular description can be very useful to scholarly research, but what are its specific benefits for Indigenous individuals and communities, and what might be the dangers? To what extent are archivists creating a new record or information resource about Indigenous people through their descriptive processes? What kinds of coordination might need to be in place or new descriptive techniques devised to address privacy and other concerns of Indigenous and other vulnerable communities, past, present and future, while also facilitating as much access as possible by audiences with different needs?

\subsection{Concluding remarks}

Simultaneously representing the interests and perspectives of multiple creators and co-creators equitably, respectfully and systematically, as well as meeting the descriptive needs of others who will be users of archival materials is complex. It is widely recognized that user communities can be internally diverse and their membership non-exclusive. They may share some characteristics and perspectives, but not others, and their composition, nature, and needs continuously evolve. Communities of records present similar considerations for description in that they may encompass multiple creators and co-creators, each with their own kinds of relationships with and interests in the records; they are dynamic in that their sense of the shared present as well as the shared past constantly evolves; and there are identifiable points where the interests of those who make up that community converge or diverge.

It should also be noted that approaches laid out in different sets of Indigenous protocols may not necessarily be in complete accord with one another because of their different professional and disciplinary audiences. One illustration of the variances in nuance between different Indigenous protocols on a single consideration that is relevant to archival description is how each approaches offensive, inaccurate or misleading legacy metadata that is associated with archival materials. The ATSILIRN Protocols, which address the Australian library and archival communities, reject such metadata because it does not support easy access using today's terminology. Instead they call for "nothing less than a total paradigm shift away from Eurocentric approaches to categorisation and description" (ATSILIRN 2005). The ATSIDA Protocols, developed by those involved in Indigenous research, privileges the evidential value of the materials and their metadata, and recognizes that conceptual and interpretive frames shift over time. Rather than removing it, they explain the reasons for, and alert Indigenous users to the metadata's potentially offensive nature. The $\mathrm{Na}$ tive American Protocols, developed by Indigenous and non-Indigenous archivists, acknowledge the validity of both of the above approaches, but, in addition, suggest the inclusion of additional metadata from the viewpoint of the Native American community in question (First Archivist Circle 2007).

Moreover, protocols often represent a multiplicity of Indigenous communities each with its own stories, languages, beliefs, practices, and ideas about how collections should be managed and described, and the 
conditions under which they should be made accessible. While they may set out approaches for mutual consultation and engagement, therefore, such protocols are not specific rules but rather multi-community consensual guidelines, and relationships between archives and individual communities will still need to be developed (e.g., through Indigenous advisory groups) to address particular community needs and situations. This plurality can be difficult to support for archives that need to consult with multiple Indigenous communities while also accommodating existing legislation and professionally recognized national and international best practices. Description that is responsive to the needs, epistemologies, practices, and collective identities of communities of record, whether employing a protocols-based approach or some other strategy, is going to have to be nimble and open enough to address such diversity and dynamism.

In the United States, members of the archival profession have questioned whether the pasts and legacies of its different communities (e.g., Indigenous, migrant, immigrant and African American) are too intertwined to address separately through a protocolsbased approach such as the Native American Protocols. They have also voiced concern that if each group or community, Indigenous or not, that has suffered historical injustices and inequities were to seek input in the description and management of records relating to them, archives with holdings relating to multiple communities might see their descriptive systems descend into chaos.

Such concerns highlight several questions that merit further research and development. Would the approach of co-creatorship as provenance work as a descriptive principle for materials generated by any community of records, or is it something to be applied only with specific communities where there is an imperative for the record to be "set straight," such as redressing gross miscarriage of justice or misrepresentation, or per juridical requirements? If indeed it were to act more proactively to address social justice issues, including archival reconciliation, as this paper argues, should the archival profession address each affected community individually using a protocols-based approach, should it be done on an institution-byinstitution or case-by-case basis, or should the entire archival paradigm be re-examined to identify more holistic and systematic ways to represent the different, overlapping, and dynamic co-creators, co-creator relationships, and communities of records that make up the archival multiverse?

\section{References}

Aboriginal and Torres Strait Islander Data Archive. 2010. ATSIDA

Aboriginal and Torres Strait Islander Library and Information Resources Network. 2005. ATSILIRN protocols for libraries, archives and information services. Available http://www1.aiatsis.gov.au/atsilirn/ protocols.atsilirn.asn.au/index6dfo.html?option $=$ com_content\&task =blogcategory\&id $=0 \&$ Itemid $=6$.

Archival Education and Research Institute (AERI) Pluralizing the Archival Curriculum Group (PACG). 2011. Educating for the archival multiverse. American archivist 74: 69-101.

ATSIDA Reference Group. Available http://www. atsida.edu.au/reference-group.

Australian Human Rights Commission. 1997. Bringing them home: report of the national inquiry into the separation of Aboriginal and Torres Strait Islander children from their families. Available http:// www.hreoc.gov.au/social_justice/bth_report/report/ content page full.html.

Bantin, Philip C., and Bernbom, Gerald. 1996. The Indiana University electronic records project: analyzing functions, identifying transactions, and evaluating recordkeeping systems - a report on methodology. Archives and museum informatics: cultural informatics quarterly 10: 246-66.

Bastian, Jeannette A. 2003. Owning memory: how a Caribbean community lost its archives and found its history. Westport, Conn.: Libraries Unlimited.

Duff, Wendy M., and Harris, Verne. 2007. Stories and names: archival description as narrating records and constructing meanings. In Harris, Verne, $A r$ chives and justice: a South African perspective. Chicago, Ill.: Society of American Archivists, pp. 13156.

First Archivist Circle. 2007. Protocols for Native American archival materials. Available http://www2. nau.edu/libnap-p/index.html.

Flinn, Andrew, Stevens, Mary, and Shepherd, Elizabeth. 2009. Whose memories, whose archives? Independent community archives, autonomy and the mainstream. Archival science 9: 71-86.

Furner, Jonathan. 2009. Interrogating "identity": a philosophical approach to an enduring issue in knowledge organization. Knowledge organization 36: 3-16.

Ghosh, Durba. 2005. National narratives and the politics of miscegenation: Britain and India. In Burton, Antoinette M. ed., Archive stories: facts, fic- 
tions, and the writing of history. Durham, NC: Duke University Press, pp. 27-44.

Gilliland, Anne J. 2011. Reflections on the value of metadata archeology for recordkeeping in a global, digital world. Journal of the Society of Archivists 32: 97-112.

Gilliland, Anne, Lau, Andrew J., and McKemmish, Sue. Forthcoming. Pluralizing the archive. In $A r$ chives for maintaining community and society in the digital age. Koyasan: Koyasan University.

Hurley, Chris. 2005a. Parallel provenance: (1) what, if anything, is archival description? Archives and manuscripts 33: 52-91.

Hurley, Chris. 2005b. Parallel provenance: (2) when something is not related to everything else. Archives and manuscripts 33: 110-45.

Ketelaar, Eric. 2005. Sharing: collected memories in communities of records. Archives and manuscripts 33: 44-61.

McKemmish, Sue, Faulkhead, Shannon, and Russell, Lynette. 2011. Distrust in the archive: reconciling records. Archival science 11: 211-39.

McKemmish, Sue, Iocovino, Livia, Ketelaar, Eric, Melissa Castan, and Russell, Lynette. 2011. Reset- ting relationships: archives and indigenous human rights in Australia. Archives and manuscripts 39: 107-44.

Nakata, Martin, Byrne, Alex, Nakata, Vicky, and Gardiner, Gabrielle. 2006. Mapping the Aboriginal and Torres Strait Islander Protocols for libraries, archives $\mathcal{E}$ information services: research report. Available http://nesstar.assda.edu.au/ASSDAData/reports/ ASSDA.REPORT.01159.pdf.

Russell, Lynnette. 2006. Indigenous records and archives: mutual obligations and building trust. Archives and manuscripts 34: 32-43.

Stoler, Ann Laura. 2009. Along the archival grain: epistemic anxieties and colonial common sense. Princeton, NJ: Princeton University Press.

United Nations. 2007. Declaration on the rights of indigenous peoples. Available www.un.org/esa/socdev/ unpfii/documents/DRIPS_en.pdf.

Wurl, Joel. 2005. Ethnicity as provenance: in search of values and principles for documenting the immigrant experience. Archival issues 29: 65-76. 